ISSN 2217-8090

UDK 005.552.1:[007:004]

Original paper/Originalni naučni rad

\title{
AN OPNET BASED NOVEL CROSS-LAYER MODEL FOR ANALYZING SOA-BASED INFORMATION SERVICES
}

\author{
Aleksandar Kolarov ${ }^{1, *}$, Gi Tae Keith Kim ${ }^{1}$ \\ ${ }^{1}$ Applied Communication Sciences, \\ Telcordia Drive, Piscataway, New Jersey, USA
}

\begin{abstract}
:
Service Oriented Architecture (SOA) based information systems and services are finding wider applicability in complex, mission-critical operational environments. In order to effectively help design and prepare information sharing services for such complex operational environments, designers have to consider various architecture tradeoffs and interactions across the SOA application, communication middleware and network infrastructure layers. In this paper, we describe a novel modeling and analysis framework for analyzing and evaluating the performance of SOA-based information services and their myriad design \& deployment options over varying network infrastructures under varying conditions of network load. Our modeling framework developed in OPNET defines critical Measures of Effectiveness (MOEs) to characterize performance of candidate applications considering the SOA interaction characteristics, as well as the underlying SOA communication middleware and network infrastructures. Our modeling framework provides the ability to both analyze as-is application scenarios as well as potential alternative architectures that may include differing application characteristics (e.g. increase in the application's data generation rate), varying the SOA interaction characteristics (e.g. pub-sub vs. requestresponse communication styles, use of JSON vs. XML for data-interchange, use of SAML security tokens etc.) or network characteristics (e.g. varying background traffic and latency). A key feature of our modeling framework is the ability to uncover issues resulting from adverse or unforeseen interactions between the Application, SOA interactions and Network layers. Our initial results on evaluating Information sharing services across enterprise inter-agency infrastructures interconnected by public/private networks demonstrate the viability of our cross-layer modeling framework.
\end{abstract}

\author{
Key words: \\ SOA, \\ OPNET, \\ cross-layer, \\ publish-subscribe, \\ request-response, \\ modeling.
}

\section{INTRODUCTION \& RELATED WORK}

As a part of the transition of the National Airspace System (NAS) to Next Generation Air Transportation System (NextGen), there are critical challenges from the perspective of information collection, processing, analysis and dissemination. The main goal is to transform NAS information systems and services into a Service Oriented Architecture (SOA) based agile information-centric system, able to effectively and efficiently deliver the right information to the right people at the right time, through improved common situational awareness and decision support capabilities. 
In order to effectively help design and prepare information sharing services for such complex operational environments, designers have to consider various architecture tradeoffs and interactions across the SOA application, communication middleware and network infrastructure layers. There are specialized simulation tools addressing communication network performance evaluation (OPNET, 2011) and tools addressing purely SOA behavior (Brebner, 2008); however, there is a paucity of tools that consider the end to end system behavior from the SOA application down to the network layer.

Paul Brebner (2008) presents a tool for performance modeling of Service Oriented Architectures. The tool enables performance models to be generated from available architectural artifacts and performance data. While this tool can model complex systems leveraging service composition, it does not explicitly address the underlying communication network fabric. Our approach in contrast is centered on extending a well- known network simulation environment to include the SOA stack, thus providing a comprehensive SOA simulation framework.

In this paper, we describe a novel modeling and analysis framework for analyzing and evaluating SOA-based information services and their myriad design \& deployment options over varying network infrastructures under varying conditions of network load. The focus of our modeling framework is on characterizing performance of candidate applications considering the SOA interaction characteristics, as well as the underlying SOA communication middleware and network infrastructures. In particular, we define several critical Measures of Effectiveness (MOEs) for SOA-based information services that can be evaluated from both the Service Providers' and Consumers' points of view. These MOEs can be used to quantify \& evaluate whether a specific SOA solution and deployment meet the Quality of Service (QoS) requirements. Further, the identified MOEs enable comparisons of the effectiveness of the various design and deployment strategies ranging from the SOA Application to the SOA communication middleware and Network Infrastructure layers.

The modeling framework provides the ability to both analyze as-is application scenarios as well as potential alternative architectures that may include differing application characteristics (e.g. increase in the application's data generation rate), varying the SOA interaction characteristics (e.g. pub-sub vs. request-response communication styles, use of JSON vs. XML for data-interchange, use of SAML security tokens etc.) or network characteristics (e.g. varying background traffic and latency).

A key feature of our modeling framework is the ability to uncover issues resulting from adverse or unforeseen interactions between the Application, SOA interactions and Network layers. For example, in evaluating the efficacy of alternative SOA interaction patterns in networks with high loss communication lines (e.g. radio links), synchronous SOA interaction such as the request-reply message exchange pattern may be less effective than asynchronous interactions such as the pub-sub pattern both in terms of throughput and response time. The framework can also quantify the tradeoffs involved in SOA security architectures, such as local vs. remote authentication, encryption and the use of security tokens or digital certificates. Another example is the ability of the framework to help quantify the need for SOA layer reliability mechanisms over different network infrastructures.

In the following sections we detail related work and our Measures of Effectiveness (MOEs) for SOAbased information services. We then describe our novel cross-layer modeling framework and its configuration and design options to evaluate various tradeoffs and scenarios, as well as some initial results on evaluating Information sharing services across enterprise interagency infrastructures interconnected by public/private networks.

\section{MEASURES OF EFFECTIVNESS}

SOA promises many benefits that are essential for mission critical operational Systems: flexibility and agility to adapt to new events or changing user needs; reduced development cost by defining and employing components that can be orchestrated and reused; improved interoperability and information dissemination through use of standards-based technology; and the ability to rapidly introduce new capabilities by composition of existing services.

There are also challenges with realizing SOA, however, that if not carefully addressed, negatively impact the value of introducing SOA and significantly adds to the deployment risk. Specifically, the use of SOA in a mission critical environment requires stringent QoS requirements such as performance and reliability guarantees that are not usually accounted for in typical WEB 2.0 deployments. 
Meeting QoS requirements in a SOA deployment is achieved by carefully selecting the proper topology, architecture, communication pattern, communication middleware, adapting to the network infrastructure and by balancing the ripple effects that each choice adds to the overall system QoS. Establishing SOA QoS metrics enables the measurement and comparison of specific SOA deployment choices and thence navigation of the solution space in search of optimal configurations.
Kolarov A., Gi Tae K. $\diamond$ An OPNET based novel cross-layer model

As such, this section identifies these QoS metrics by defining Measures of Effectiveness (MOEs) for SOA-based information sharing services. The proposed MOEs are drawn from quality dimensions for SOA-based applications and network performance measurements. Leveraging the Quality Dimensions for Distributed Computing, we harmonized two prominent studies; the Software Engineering Institute Study of Quality Attributes (Barbacci et al., 2011) and the UML Profile for QoS (UML, 2008), resulting in the taxonomy illustrated in Figure 1.

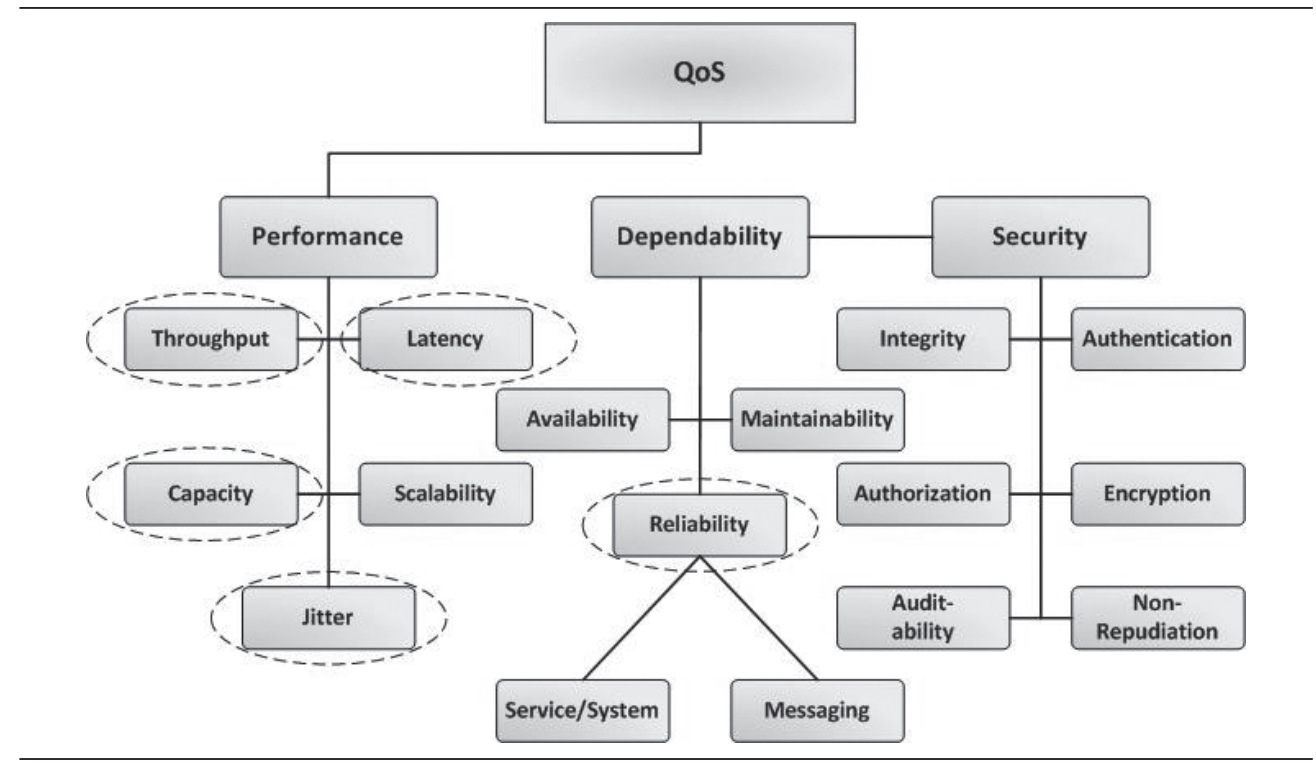

Figure 1: SOA QOS Taxonomy

For the purpose of the modeling framework analysis we focus on the Performance and Dependability quality dimensions with key performance metrics (circled in Figure 1) corresponding to Throughput, Latency and Jitter as well as the Reliability metric under the Dependability dimension. While we also account for the performance impacts associated with various security measures, we do not qualify the effectiveness of the security measures in our current work.

\begin{tabular}{lll}
\hline \multicolumn{1}{c}{ MOE Category } & \multicolumn{1}{c}{ QoS Metric } & \multicolumn{1}{c}{ Description } \\
\hline Throughput & $\begin{array}{l}\text { Goodput, SOA Through- } \\
\text { put, Network Throughput }\end{array}$ & $\begin{array}{l}\text { Application level throughput, SOA level throughput } \\
\text { and raw Network throughput in bits per unit time }\end{array}$ \\
\hline Data Efficiency Factor & Ratio of Goodput to SOA layer throughput \\
\hline Service Reliability & $\begin{array}{l}\text { Service or Transaction } \\
\text { Latency }\end{array}$ & $\begin{array}{l}\text { Application interaction latency as defined by SOA } \\
\text { communication style (e.g. publish-subscribe or } \\
\text { request-response) }\end{array}$ \\
\hline Packet Loss Rate (PLR) & $\begin{array}{l}\text { Ratio of lost packets to transmitted packet } \\
\text { SOA Service Reliability }\end{array}$ & $\begin{array}{l}\text { Ratio of failed service invocations to total service } \\
\text { invocations }\end{array}$ \\
\hline
\end{tabular}


Table 1 relates the MOE category with the QoS Metrics and provides a description of the instrumented measurement in our modeling framework, and can be used to compare simulation scenarios and analyze tradeoffs corresponding to design and architecture choices.

\section{MODELING FRAMEWORK}

The SOA modeling framework is constructed using OPNET Modeler, a discrete event simulation toolkit (OPNET, 2011) and leverages many of the underlying capabilities of OPNET with respect to network infrastructure (routers, switches, links, etc.), background traffic and the standard TCP/IP stack. On top of this base, we have developed detailed custom models of SOA service and middleware layers, information message exchanges and statistics that comprise the multi-layer, configurable SOA Modeling Framework.

Network scenarios modeled in OPNET mimic the inter-agency Net-Enabled Test Environment (NETE), a number of agency enterprise infrastructures that are interconnected by public/private Wide Area Networks (WANs) that span the continental U.S. Figure 2 depicts a sample network scenario where each of the colored ovals is a representative public/private WAN with associated core and edge routers and sources of background traffic. These WANs interconnect agency sites that are indicated by small red circles. The right side of the figure depicts a sample enterprise infrastructure, modeling servers and workstations interconnected by LAN components such as switches, routers and protected by firewalls.
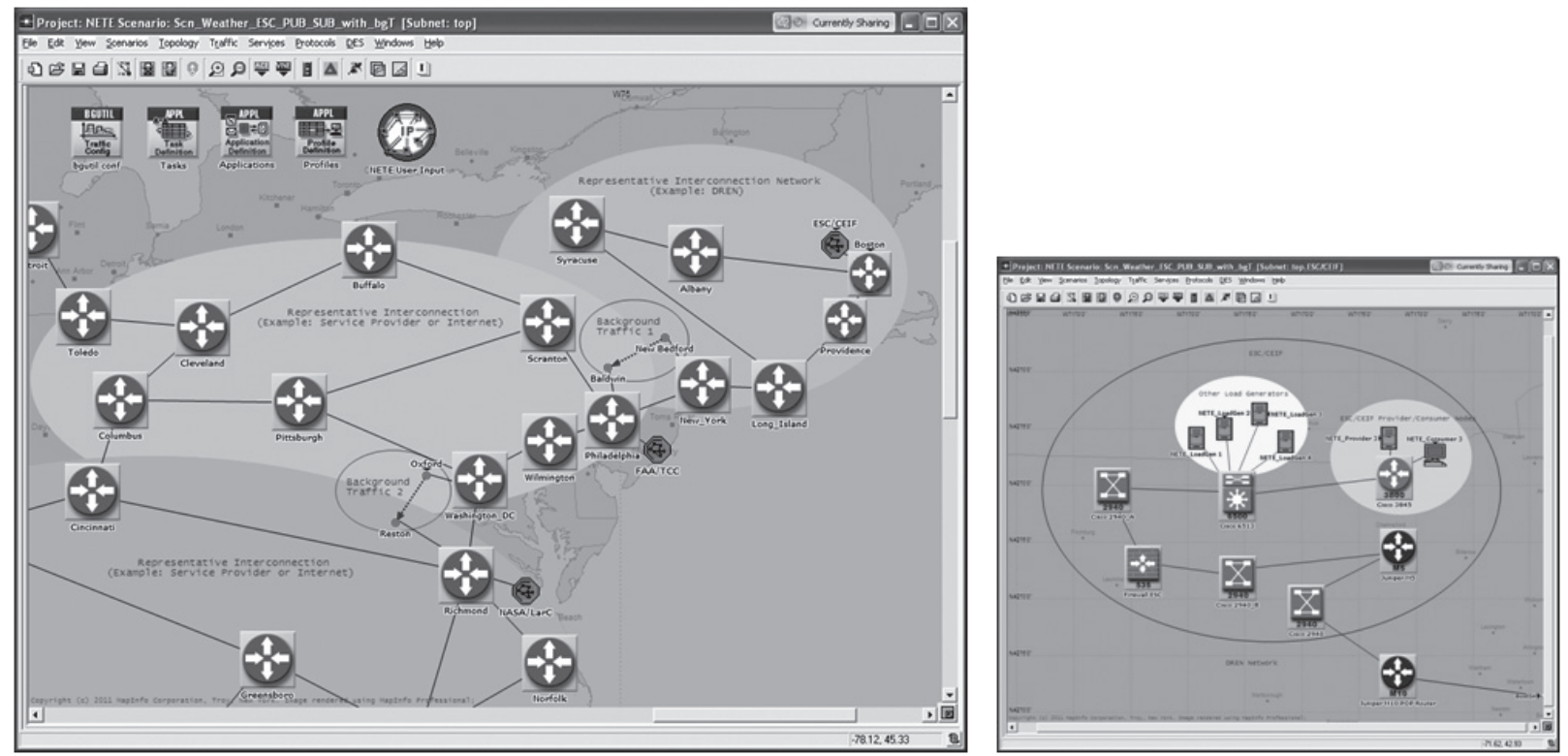

Figure 2: Network scenarios depicting WAN interconnection and a sample site enterprise infrastructure

Our simulation framework includes the following main types of network elements (NEs): (1) a SOA-capable node model that can serve as a server or workstation, to function as Service Provider and/or Consumer, (2) Security device model such as Firewall, DMZ servers (3) WAN \& LAN routers, switches, etc. and (4) Background traffic nodes that can be used to inject cross traffic. These NEs can be interconnected with communications links of various bandwidths, reconfigured in various topologies and locations, and subjected to various types of network conditions (failures, congestion, etc.) to adapt the network scenarios to real-world deployments.
Further, the deployment of Service Providers and Consumers, the information sharing services (e.g. weather), the frequency and type of information exchange etc. can also be modified to suit.

Each network element is characterized by an OPNET node model that spans the layers in the OSI stack from Application to Physical layer. In order to facilitate modeling and performance analysis of SOA information services, we have developed a custom SOA Service \& Middleware Sub-layer that abstracts real-world logical and functional SOA features as depicted in Figure 3. The key logical and functional components of this layer are outlined below: 


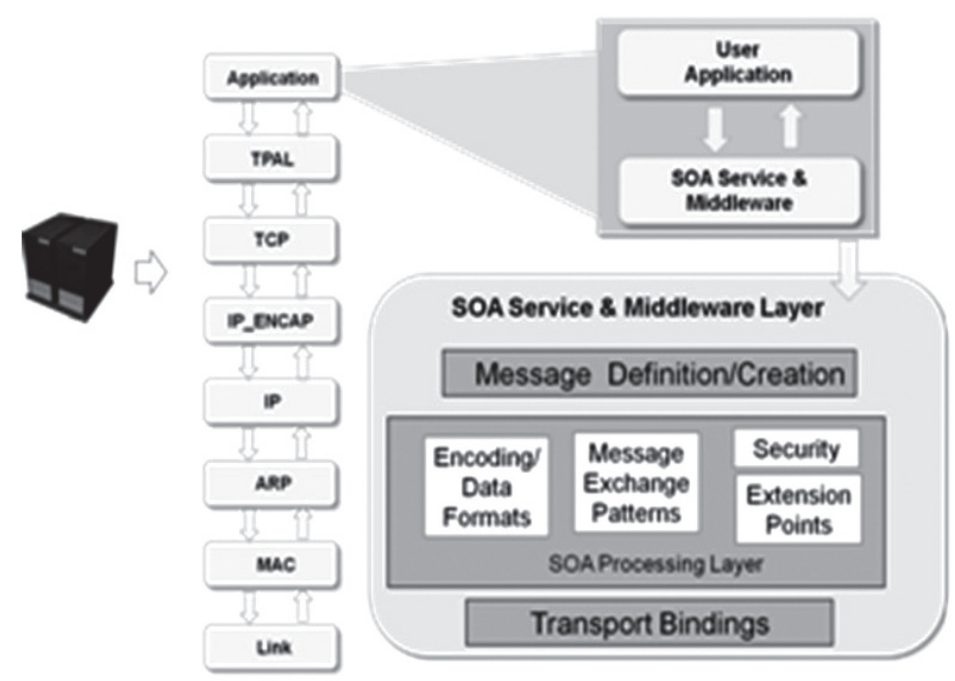

Figure 3: Node model depicting our custom SOA Service and Middleware sub-layer implementation

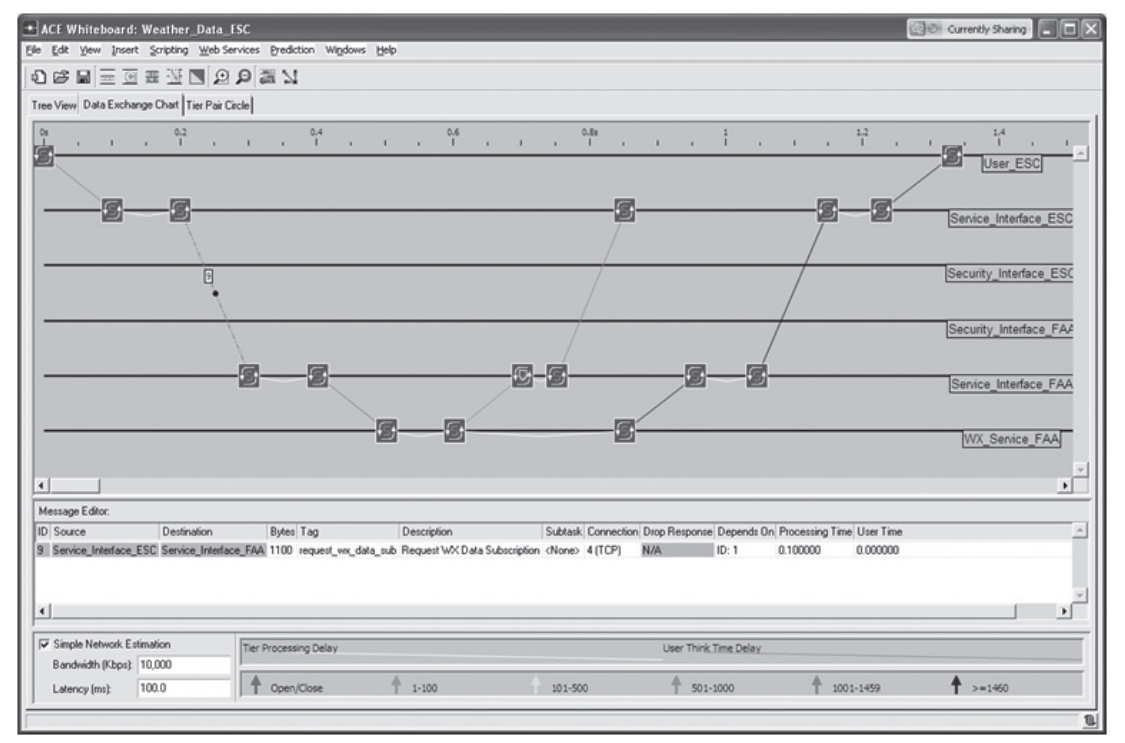

Figure 4: Information Service Messages and logical role definitions using the graphical ACE Whiteboard

Message Definition \& Creation component includes a graphical user-interface in OPNET's ACE Whiteboard (depicted in Figure 4) that can be used to define messages, and logical roles, such as Service Provider, consumer, security interface, etc. Each of the horizontal black lines in Figure 4 corresponds to a logical role (or tier), that can then be tied to a physical infrastructure in a network scenario. Information exchange messages (the vertical lines between the logical tiers) and their characteristics such as application message sizes, names and associated processing delays can be specified using this component. Options and functions applying to these messages can be specified by using the SOA Processing layer functions described below.
The model includes a graphical interface to design or customize complex information service interactions between various logical tiers. User parameters drive a host of model behaviors ranging from message formats, processing delays, logic, message exchange patterns, etc.

The SOA Processing Layer contains the functional components that constitute core SOA layer features.

Encoding/Data Formats: These functions factor the impact of various data formats and encoding sizes on SOA layer overheads and thereby message sizes and processing times. Key parameters that impact message size include: type of message payload (XML compressed, XML, binary, etc.), original 
payload size, the size of message header, and data compression ratio.

Message Exchange Patterns: These functions aid in the construction of different message exchange patterns such as Request-Response or PublishSubscribe interactions. For instance, in PublishSubscribe interactions this layer incorporates asynchronous timers that schedule publish events to subscribed clients at user-specified intervals.

Security: This function block includes support for WS-Security features such as local or remote authentication using SAML tokens or digital certificates, encryption and the associated information service impacts such as processing delays and security message exchanges. Security features can be enabled or disabled for information service interactions, and various parameters tuned to assess performance impact, e.g. the impact of different SAML token expiry timers.

In general, the various layers in the SOA layer also compute appropriate processing delays, i.e. the latency occurred by all the activities in the SOA layer in the provider and consumer nodes. Once the delay is determined, the simulation model schedules the processing delays as discrete events in simulation event queue before scheduling message transmission and after message reception, to simulate the message processing delays occurred in the SOA layer. Parameters that affect the processing delay can include communication parameters (message size, data compression ratio etc.) as well as computing infrastructure (CPU speed, memory, etc.).

The Transport Bindings layer binds to underlying transport mechanisms such as HTTP for Web Services, and thence delivers or receives messages to/from the SOA layer.

\section{SIMULATION SCENARIOS AND SETUP}

We have created a set of simulation scenarios to evaluate the performance of SOA-based information services with various SOA-related parameters under varying networking conditions. This section outlines the scenario setup and presents the performance measurement and analysis on the QoS metrics based on the MOEs defined in our modeling framework.

Three sets of scenarios have been experimented to measure the SOA service performance under the following three different service and network conditions:

- Scenario \#1: Gain in performance from encoding: use of XML compared with use of compression.

- Scenario \#2: Performance tradeoffs from Security options: local or remote authentication.

- Scenario \#3: Impact of network congestion on End-to-end service latency and packet loss rate.

\section{SCENARIO DESCRIPTION}

Topology and network setup: Figure 5 shows the network topology where a set of WAN routers are interconnected via OC-3 links, with a set of SOA capable nodes (consumer and provider nodes) connected via access links. The cross traffic is injected on the link between NY and Philadelphia, which serves as the bottleneck link. OPNET's Background Traffic utility is used to generate the cross traffic.

SOA services and traffic generation: Scenario \#1 and \#2 include the Request-Response service, and Scenario \#3 includes Publish-Subscribe service. The SOA consumer is located in the Service Consumer site and SOA service provider is located in the Service Provider site. For Request-Response service, the consumer requests a service and the provider responds with the requested data. For Publish-Subscribe service, the consumer subscribes to a service and the provider sends the subscribed data at regular intervals. For Request-Response service, the average request inter-arrival time is set to 300 seconds (exponentially distributed). For Publish-Subscribe service,

Figure 5: Network topology for the three experimental scenarios

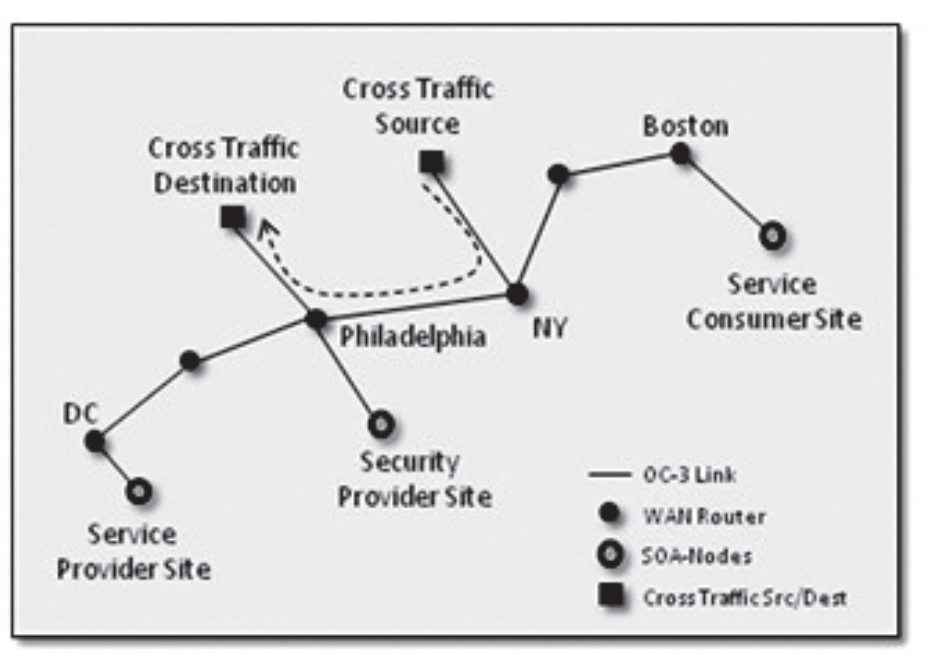


the publish interval is set to 600 seconds. Both the request and response message size is set to 1000 bytes. Service starts at 500 -second from the start of simulation which lasts for the duration of simulation which is set to 1 hour. At the start of service, authentication process takes place. The authentication is performed remotely by the server in the Security Provider site. Password-based authentication is used in the Scenario \#1 and \#2, and Token-based authentication is performed in the Scenario \#3.

\section{PERFORMANCE EVALUATION AND INITIAL RESULTS}

Scenario \#1 - Gain in Performance from Encoding: This scenario evaluates the impact of message compression on Data Efficiency. Performance results from Scenario \#1 simulation runs are presented in the Table 2.

In the table, the first column shows the message compression ratio: $0 \%$ corresponds to the case when an $\mathrm{xml}$ message is sent without compression, and $15 \%, 30 \%, 45 \%$ and $60 \%$ are values for the compression ratio when the message is sent using an encryption scheme. The average data payload used in this experiment is 3,199.6 bytes. Any SOA message car-
Kolarov A., Gi Tae K. $\diamond$ An OPNET based novel cross-layer model ries this payload and an additional xml overhead. The second column denotes the throughput in bps at the SOA layer. This throughput is the highest in case when there is no message compression. Data efficiency that is defined as the ratio of the user payload data and total message data is presented in the third column of the table. As expected the case without message compression shows the worst performance (the lowest data efficiency).

Scenario \# 2 - Performance tradeoffs from Security options: This scenario is to compare the performance in the latency category, resulting from the temporal overhead when authentication is performed locally vs. remotely. At the start of each Request-Response cycle, authentication is performed. Figure 6 shows a comparison of the average service latency (end-to-end message delay) when authentication is performed locally (left) and remotely (right). As anticipated, remote security authentication adds additional latency to the end-to-end message delay. Depending on the application QoS requirements, this additional delay may be a significant impairment to deployment of remote security authentication.

Scenario \#3 - Impact of network congestion: This scenario evaluates the impact of the network congestion on the SOA traffic. Cross traffic is used to inject

\begin{tabular}{ccc}
\hline Compression Ratio & SOA Throughput (bps) & Data Efficiency \\
\hline $0 \%$ & 12121.6 & 0.263983303 \\
\hline $15 \%$ & 11065.6 & 0.289175463 \\
\hline $30 \%$ & 10009.6 & 0.319693095 \\
\hline $45 \%$ & 8953.6 & 0.357386973 \\
\hline $60 \%$ & 7897.6 & 0.405186386 \\
\hline
\end{tabular}

Table 2: Data Efficiency and SOA Throughput under varying degree of compression ratio

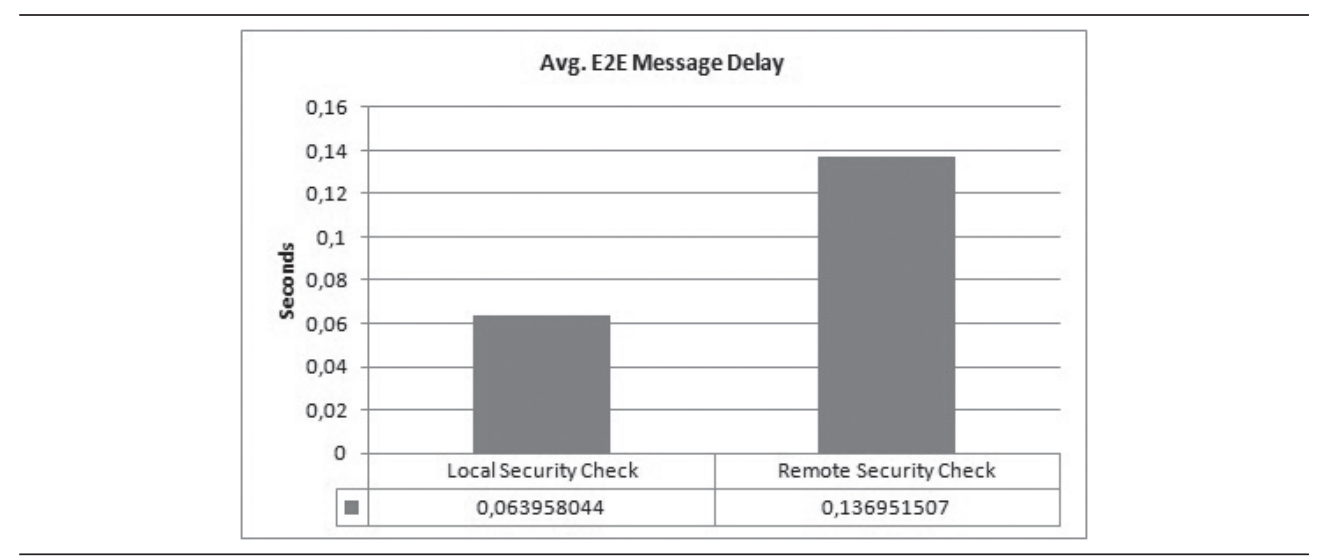

Figure 6: Average Service latency for local and remote authentication 
congestion on the link between NY and Philadelphia, where the user traffic passes through. Four different levels of cross traffic (50\%, 70\%, 80\%, and $90 \%$ of link bandwidth) are used to observe the end-to-end SOA message delays and their variances, and packet drop rate at the bottleneck link (NY $\Leftrightarrow$ Philadelphia) where the cross traffic and user traffic meet.
Figures 7, 8, and 9 show the average service latency and its variance, and average packet drop rate measured at the NY bottleneck link, respectively. In all three QoS measurement categories, the performance is sustained until the level of cross traffic reaches to around 70 percent of the link bandwidth. From 80 percent, the performance of the SOA traffic drastically deteriorates, resulting in an average of

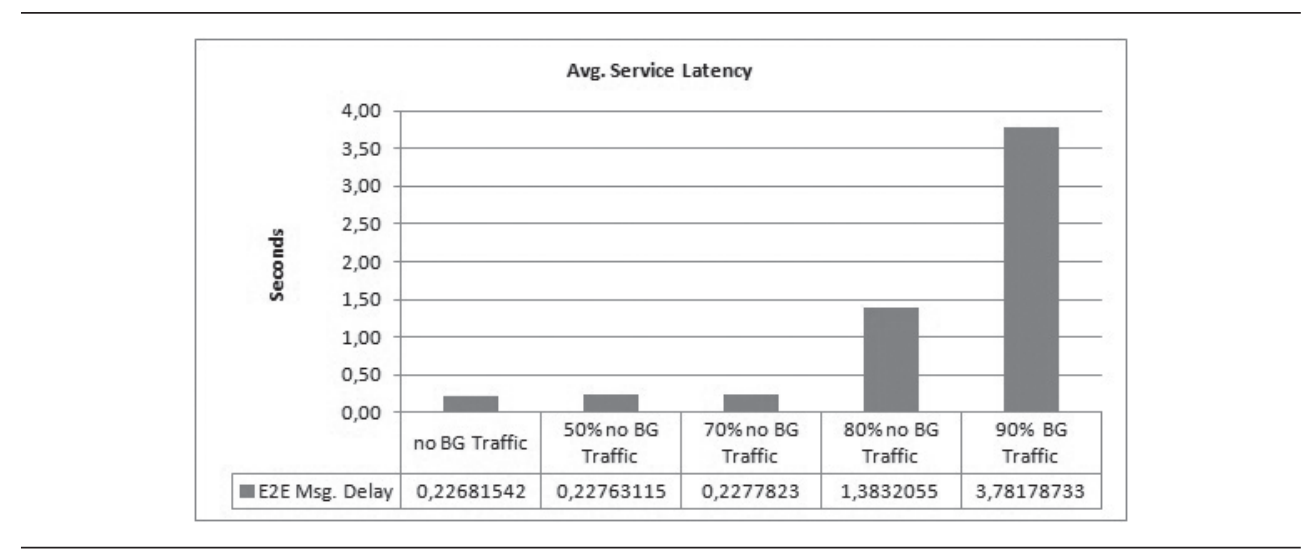

Figure 7: Average Service latency for varying cross-traffic

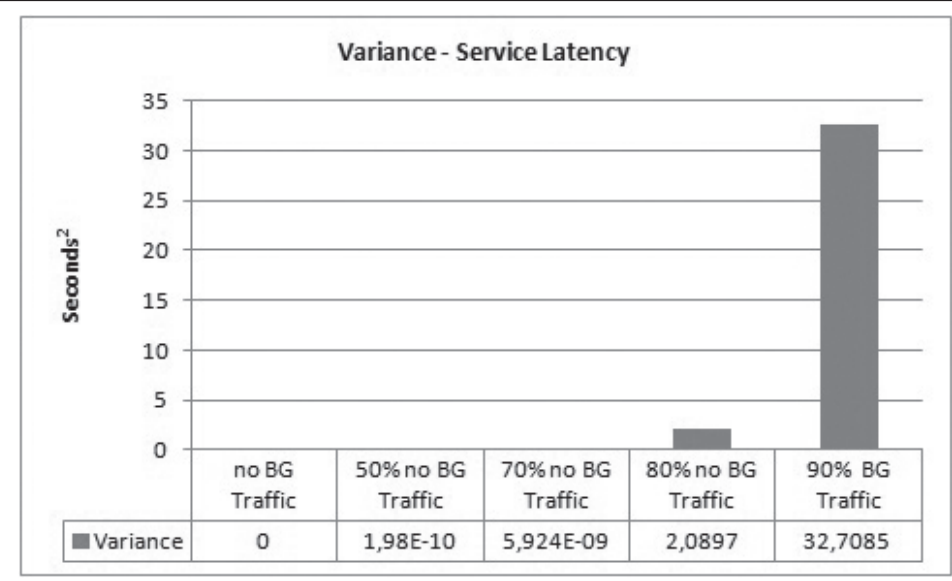

Figure 8: The variance of Service latency for varying cross-traffic.

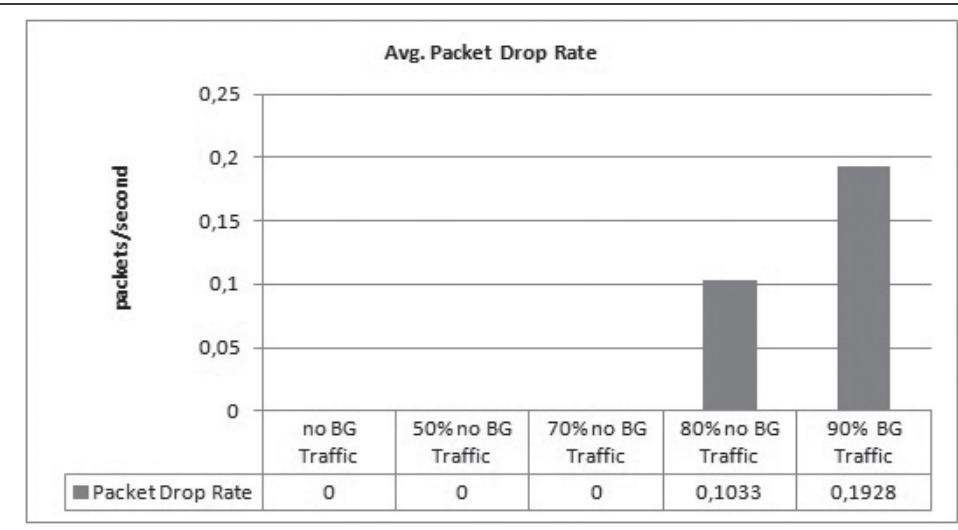

Figure 9: The average packet drop rate at the bottleneck link between NY and Philadelphia 
$\sim 3.7$ seconds for service latency at $90 \%$. The variance of the service latency and packet drop rate at the bottleneck link also drastically increase accordingly.

\section{SUMMARY AND NEXT STEPS}

In this paper, we have presented a novel modeling framework for analyzing and evaluating SOA-based information services and their myriad design \& deployment options over varying network infrastructures under varying conditions of network load. Our framework implements a layered approach with a number of critical design \& deployment capabilities at the SOA service and middleware layer that will aid designers in evaluating the ability of an information service design to meet specific QoS requirements.

Our initial results show the feasibility of evaluating the performance impacts of various SOA design choices or network conditions on end-to-end performance. In our future work, we intend to extend our modeling framework to include more sophisticated features at the SOA service \& middleware layer, for instance SOA layer reliable messaging options, as well as support additional network infrastructure capabilities, such as Air-Ground aircraft networks and mobile ad-hoc networks.

\section{REFERENCES}

Barbacci, M., et al. (1995) Quality Attributes. s.l. Technical Report CMU/SEI-95-TR-021, Software Engineering Institute, Carnegie Mellon University.

Brebner, P.C. (2008) Performance modeling for service oriented architectures. Companion of the 30th international conference on Software engineering, 10-18 May 2008 Leipzig. Proceeding ICSE Companion, 953-954.

OPNET (2011) Modeler Accelerating network R\&D [online]. Available from: http://www.opnet.com/solutions/ network_rd/modeler.html [accessed: 29 November 2011].

UML Profile for Modeling Quality of Service and Fault Tolerance Characteristics and Mechanisms Specification. s.l. (2008) Object Management Group, April 2008. Version 1.1.

\section{NOVI SLOJEVITI MODEL ZA ANALIZU SOA INFORMACIONIH SERVISA ZASNOVAN NA OPNET-U}

\section{Rezime:}

Informacioni sistemi i servisi koje se baziraju na servisno orijentisanoj arhitekturi (SOA) pronalaze širu primenu u složenim, operativnim okruženjima. Da bi uspešno pomogli u dizajniranju i pripremi servisa koji dele informacije za tako složena operativna okruženja, projektanti moraju da razmotre različite kompromise i interakcije kroz SOA aplikacije, komunikacijski srednji sloj (middleware) i slojeve mrežne infrastrukture. U ovom članku opisujemo novi okvir analize i modelovanja za analiziranje i ocenu performansi informacionih servisa koji se zasnivaju na SOA, kao i mnoštva opcija za njihovo projektovanje i uvođenje kroz različite mrežne infrastrukture pod različitim uslovima mrežnog opterećenja. Naš okvir modelovanja razvijen u OPNET-u definiše kritične mere efektivnosti (MOE). One opisuju performase mogućih aplikacija koje uzimaju u obzir karakterisike SOA interakcije, kao i osnovni srednji sloj SOA komunikacije i mrežne infrastrukture. Naš okvir modelovanja daje sposobnost analiziranja postojećeg scenarija aplikacije, kao i potencijalne alternativne arhitekture koje mogu da sadrže različite karakteristike aplikacije (npr. povećanje brzine u generisanju podataka), variranja karakteristika SOA interakcije ili karakteristike mreže. Glava osobina našeg okvira modelovanja je mogućnost otkrivanja problema koji nastaju kao rezultat neprijateljskih ili nepredviđenih interakcija između aplikacija, SOA interakcija i slojeva mreže. Naši prvi rezultati u proceni servisa za deljenje informacija kroz infrastrukturu preduzeća, koji su povezani javnim ili privatnim mrežama, pokazuje izvodljivost našeg okvira modelovanja kroz različite slojeve.

Ključne reči:

SOA,

OPNET,

slojevitost, objavljivanje-pretplata,

zahtev-odziv, modelovanje.

Received: January 20th, 2012

Correction: February 8th, 2012

Accepted: February 23rd, 2012 